\title{
'The first challenge in managing anxiety is recognising it'
}

\author{
Kate Quinlan seeks perspectives on alleviating patient \\ anxiety from UK dental professionals.
}

I

\section{ntroduction}

A recent $B D J$ study showed that

playing music during minor oral surgery helped patients feel more at ease: https://www.nature.com/articles/ s41415-019-1162-1. ${ }^{1}$

Authors from Turkey have investigated the use of lavender oil in reducing anxiety in dental patients: https://www.ncbi.nlm.nih. gov/pubmed/31505191. ${ }^{2}$

This news story published in The Irish News also mentions a study focusing on lavender oil for child dental patients: http:// www.irishnews.com/lifestyle/2020/01/16/ news/health-facts-soothe-children-s-fear-ofdentist-with-a-sniff-of-lavender-1806701/. ${ }^{3}$

I asked a selection of UK dentists: How do you help alleviate patients' anxiety in your

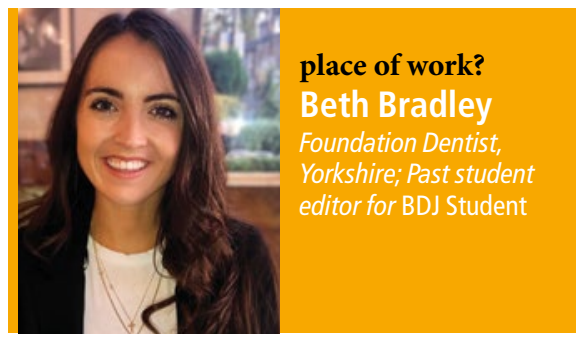

WE ALL KNOW that dental treatment, even just the average routine dental check-up, can induce anxiety in most people. ${ }^{1}$

I am currently experiencing my first year working in general practice, and I, like every other dentist frequently hear the phrases: 'Oh I'm terrified of the dentist' or 'It's not you love, I hate all dentists'.

I have thoroughly enjoyed changing patients' perspective of the dentist and have already witnessed the great impact a bit of time, understanding and attention can have in the delivery of patients' care. Nothing makes me happier than hearing feedback like: 'I felt safe,' 'I felt empowered' or 'I felt cared for'.

This brings me to my first method of trying to alleviate patient anxiety which is time. From the outset I encourage patients to tell me how they feel at the dentist, to open up about specific things which make them nervous. I take time for this conversation, to listen to them and I aim to empower them, ensuring they know they can be in control. No treatment is ever started without ensuring the patient knows that at any point if they are uncomfortable or worried they just have to let my nurse or myself know with a pre-assigned hand signal and we will pause treatment. This has been an invaluable technique for empowering my patients.

The next technique I have been using is music. I was thrilled to see the recent research by Gupta and Ahmed ${ }^{1}$ whose pilot study showed promising evidence for the positive effects of music in the dental setting. Already from my early career experience I have seen the obvious impact music can have on my patients, and now we know music not only has positive psychological impacts but physical impacts on vital signs too. ${ }^{4} \mathrm{I}$ am fortunate to be able to choose playlists and music genres for my patients in my surgery and have seen first-hand the benefits some calming music, or a bit of Disney for the kids, can have.

This brings me to a personal goal I have set for myself which is to always provide a positive experience for my paediatric patients. We know that dental anxiety often stems from a traumatic early childhood dental experience. ${ }^{5}$ Therefore I see every child patient as an opportunity to create a dental-anxiety-free adult. From my teaching at Leeds Dental School I was equipped with the many skills and techniques proven to help when treating children. However, it was not until I was in the surgery with a young nervous child and fully responsible for their care that I was aware of how effective these methods can be.

My approach for children starts from the very beginning of their visit. Our reception staff at Eccleshill Dental are amazing, always ready with a smile and a chat for our young patients. This often sets the tone for the visit and from the moment they are at the practice the appointment is all about making them feel comfortable. We've found that a smile and some kind words (along with the promise of a sticker or two) goes a long way!

Calming children's music can often be heard coming from my surgery and I have found this super helpful for both distracting and relaxing my patients. I have even had a few reviews from parents saying their children are asking to come back for another visit to the dentist! This can only be a promising sign.

I am extremely interested in the recent study from Turkey in which children receiving dental care inhale lavender oil three minutes before dental treatment. ${ }^{2}$ I have used lavender oil myself as an anxiolytic and relaxant. I would love to be able to use this technique if it is to be proven effective for use in general practice. However, I feel that in practice it would be imperative to consider the setting for the delivery of this intervention. A busy practice waiting area is not always the most calm-inducing environment. I eagerly await more evidence on this matter.

So in my opinion alleviating patients' anxiety is all about CARE. As long as we care for every one of our patients, ensure we are always looking after them to the best of our ability and we provide a safe, comforting calming environment, we will have made a difference. 


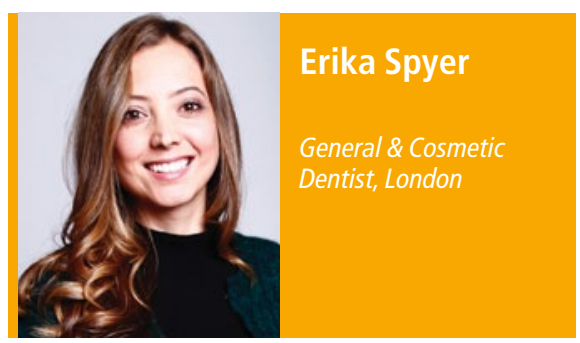

WORKING IN A fully private practice gives me the opportunity to spend more time with my patients - particularly if they feel anxious about dental treatment.

I tend to explain everything I am about to do in detail using the tell-show-do technique for children and also for adults. By doing this, the patient knows what to expect and feels they are in a safe environment.

At our practice we have a screen projector from which our patients can select a film or TV series to watch whilst we are doing treatment - this has proven to be very successful, particularly with anxious patients.

We also have wireless headphones that block out our dental equipment noise. We get a lot of feedback to say this makes the experience less stressful.

Among the most popular shows for adults are Blue Planet and Friends and for children, it's Peppa Pig and Despicable Me!

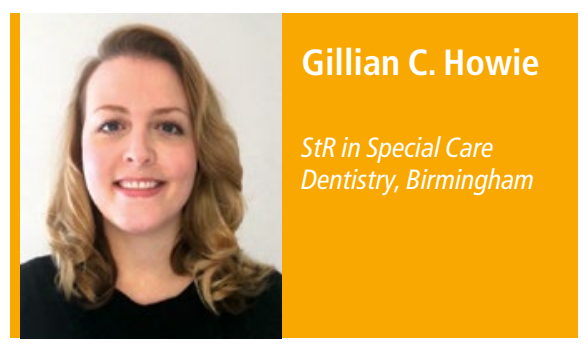

THIS IS A particularly pertinent question within special care dentistry because for one reason or another the majority of our patients are anxious when they visit us.

The way in which a patient with a learning disability or a mental illness displays their anxiety can vary greatly and I think the first challenge in managing anxiety is recognising it - aggression is not always deliberate, nor is it necessarily a sign of anger.

There are of course some instances where pharmacological anxiolysis is the most appropriate option, however there are other simple steps which can make a big difference to the overall patient experience.

The use of music within the dental surgery is a technique which I use regularly and anecdotally I have found this to be of great benefit. I was interested in the recent study published in the $B D J$ that demonstrated similar findings and mentioned the benefit of allowing the patient to choose the music in a bid to return some level of control to their situation. ${ }^{1}$ I have found that this, as well as allowing the patient to listen to the music through headphones, promotes a feeling of 'separation' and distance from the environment they find so distressing. This is also an easy way to negotiate the legal licensing issues which can cause problems, especially in large community services which span across many sites.

It is worth mentioning, however, that when using this technique, I always ensure that I have a method of continued communication with the patient. I often practise a 'check-in' technique beforehand where the patient gives a thumbs up or down signal indicating how they are coping, which is promoted by a tap on their left hand. It is crucial too that the 'stop signal' is available and respected throughout the treatment.

Finally, I am very lucky to work within a service where cognitive behavioural therapy is available to patients with dental anxieties and the dental nurses who provide this therapy have often discussed coping strategies prior to the patients' visit to the dental surgery. Some of these techniques can also be 'selftaught', and there are many apps available to equip the general public with psychological coping strategies, breathing techniques or mindfulness practices which can be of great benefit in managing dental anxiety.

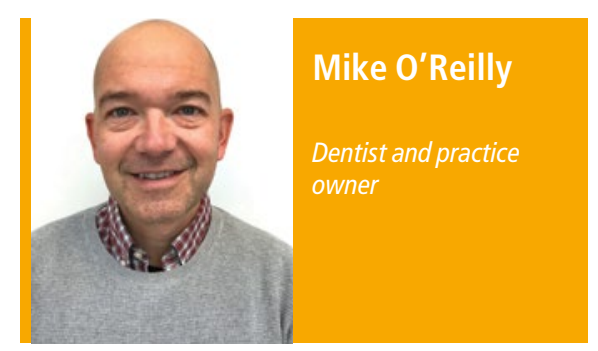

I FEEL THAT simple concise

communication is the key from the very first appointment.

Explaining everything to the patient before any clinical examination is carried out is important. It may be more appropriate to discuss things with nervous patients in a non-clinical environment if possible.

Question any previous dental treatments that have taken place (positive and negative) and encourage the patient to talk about how they feel about their teeth and any proposed treatment. Ask questions such as 'What don't you like about coming to the dentist?.

It is also important the other members of the team are sympathetic to the patient, and make the patient feel at ease in the dental practice environment, from the first contact in the reception area (quiet music helps in this respect along with a nicely decorated area with non-clinical pictures on the wall).

With children, it is sometimes necessary to have one or two appointments away from the dental chair to gain their confidence, just talking with them about brushing and gently introducing them to the clinical environment from an early age.

Allowing patients to access their own music/media (via iPods/phones) during longer procedures can also help, but only after discussion about proposed treatments.

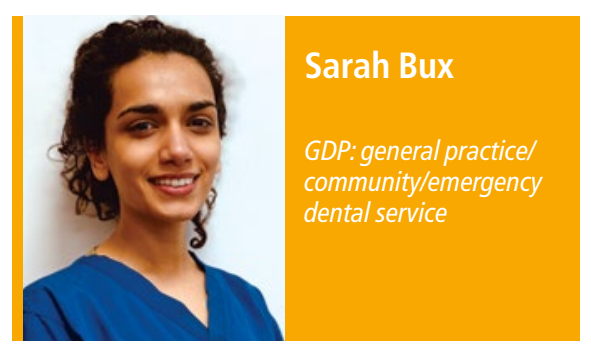

I THINK ALLEVIATING anxiety is an ongoing process of creating an environment where the patient feels safe and able to develop a trusting relationship with their dentist. The environment and the team you work alongside are vital to enhancing the patient experience.

Over the last two years, I have been using a cognitive behavioural therapy (CBT) guide developed by a team of experts, led by the University of Sheffield called 'Your teeth, you are in control'. Based on my experience I found this has really helped accelerate developing that sense of safety and trust between GDP and patient. It's aimed at 9-16-year-olds with low to moderate anxiety, but I have used it successfully on 8-year-olds as well.

\section{Take an interest in them and make them}

\section{feel like you care}

As the child enters the surgery, I guide them to sit on the nicest chair we have in the room.

I adjust the position of the chair so we are interacting on an eye to eye level. I then ask 
them about their day, their weekend plans and their interests. Essentially, I just engage them in a conversation that makes them feel like I am interested in them.

Part of the CBT guide is a 'message to dentist' form for the child to write down what they want and don't want to happen, how worried and how painful they are expecting it to be and what tools they want to use to cope with how they feel.

\section{Involve them in the experience}

To make tell-show-do fun, I like to get the kids to test out the equipment with me. For example, I hand them my mirror and ask them to check if they are able to see their eye with it. I let them press the button to lay the chair back. I give them some control by letting them assist me.

Part of the message to dentist form involves us agreeing on a stop signal and signing a contract together. This makes the process feel official solidifying the trust relationship, whilst simultaneously enhancing the level of perceived control and immersion.

\section{Give them a way to 'have their cake and eat it too'}

I give them tips on how to 'cheat' eg using a straw for their juice and being smart about when they have their sweets by confining them to meal times. Still all based on Delivering better oral health though!

\section{Debrief}

Feedback is essential for a good relationship and with the CBT guide the child can let me know what they thought about the treatment at the end of the session. It's a great way of framing the progress that's been made and emphasising the positives.

\section{Finish on a high note and rewards}

Stickers are great for the younger kids, but perhaps one of my favourite parts of the CBT guide is when the children get to decide on how they will reward themselves for progress - it has to be something inexpensive and examples are provided for them. I think one of the strangest rewards requested was being allowed to mix slime and chicken together!
In summary, I alleviate patients' anxiety by getting to know them, building a rapport with them and earning their trust! The CBT guide speeds up the process because it provides them with a platform to express themselves: https://www.sheffield.ac.uk/dentalschool/ research/person-centred-population/ child-dental-anxiety/resources.

\section{References}

1. Gupta A, Ahmed B. Experience of listening to music on patient anxiety during minor oral surgery procedures: a pilot study. Br Dent J 2020; 228: 89-92.

2. Karan N B. Influence of lavender oil inhalation on vital signs and anxiety: a randomized clinical trial. Physiol Behav 2019; 211: 112676. doi: 10.1016/j. physbeh.2019.112676.

3. Health facts: Soothe children's fear of dentist with a sniff of lavender. The Irish News 16 January 2020. Available at: http://www.irishnews.com/lifestyle/2020/01/16 news/health-facts-soothe-children-s-fear-of-dentistwith-a-sniff-of-lavender-1806701/ (accessed 11 March 2020)

4. Kim S M, Kim Y K, Myoung H. Musical intervention reduces patients' anxiety in surgical extraction of an impacted mandibular third molar. J Oral Maxillofac Surg 2011; 69: 1036-1045.

5. Knellinger M. Dr. Frederick Thurston Honours Dental Hygiene Month, Now Relieves Dental Anxiety in Auburndale, FL with Calming Sedation Dentistry. PRWEB 25 October 2016. Available at: http://www.prweb.com/ releases/2016/10/prweb13794610.htm (accessed 9 February 2020)

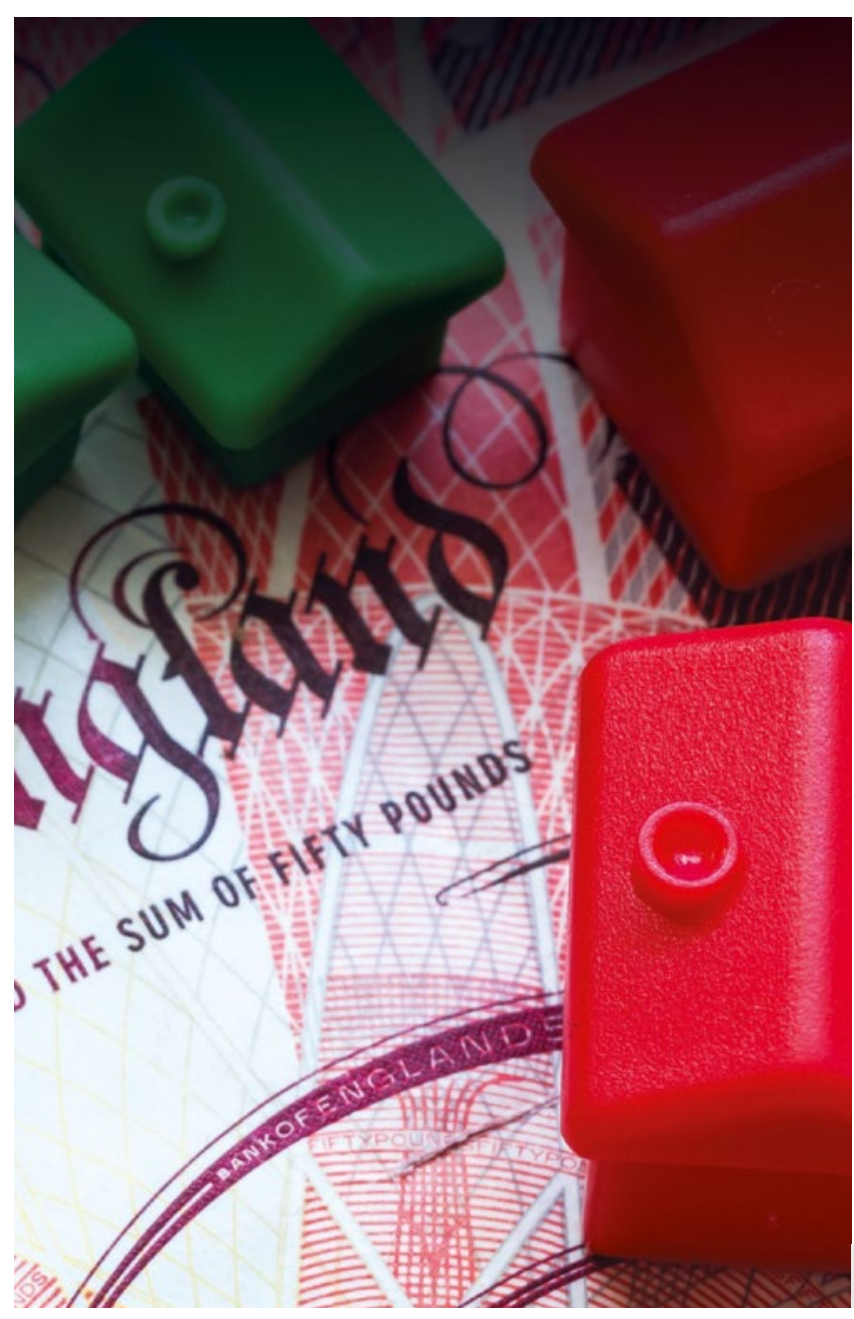

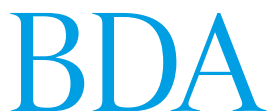

British Dental Association

\section{The business of dentistry}

We provide advice to members on:

- Contract terms and variations

- Breaches of terms and termination

- Guidance for assessing NHS performance data

- Addressing anticipated and historic underperformance against contract targets

- Financial clawback

- Breach and remedial notices and more.

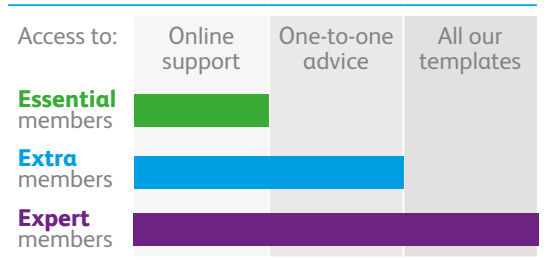

